\title{
Introduction
}

\section{Transnational Scriptworlds}

\author{
Sowon S. Park* \\ Oxford University \\ sowon.park@ell.ox.ac.uk
}

\begin{abstract}
The essays collected in this special issue think about literature through the prism of script. The emphasis is primarily on the cultural sphere inscribed by Chinese characters, or the "Chinese Scriptworld" (漢字文化圈)—China, Korea, Japan and Vietnam. All of the countries in this "scriptworld" use, or have used, Chinese characters for writing though each has its own distinct language(s). By examining the interrelations between writing, speech, thought and culture in and outside this region, the special issue investigates the significance of script and builds a case for the scriptworld as a useful analytical unit for world literature. A more complete study of world literatures, as classified by script, will bring a dimension that is currently missing from world literary theories of translation and circulation.
\end{abstract}

\section{Keywords}

the Chinese scriptworld - world literature - translation - ideographic writing - phonocentrism

* Earlier versions of this introductory essay were given at two conferences, both in 2015: the Prismatic Translation conference in Oxford and the Literary Transnationalism $(s)$ conference at University of Leuven. I am indebted to the organizers at the Oxford Comparative Criticism and Translation Programme supported by товсн (The Oxford Research Centre in the Humanities) and to Theo D'Haen. I also owe much to those from whom I received valuable criticism and feedback at various stages during the last two years while preparing this issue, not least to the editors of $J W L$, to my scriptworld authors, especially Ed McDonald, and to my colleagues in the forthcoming AHRC-funded Creative Multilingualism Programme. Ultimate responsibility for all ideas in this essay is mine. 


\section{The Chinese Scriptworld and World Literature}

This special issue brings into focus the "Chinese scriptworld," the cultural sphere inscribed and afforded by Chinese characters. Geographically, it stretches across China, Korea, Japan and Vietnam, all of which use, or have used, Chinese characters to write. This region has long been classified in Western as well as East Asian scholarship as the East Asian Cultural Sphere, the Sinosphere, or the Sinographic sphere. But, to date, attention has been directed primarily towards language and literature with too little consideration of the fundamental role of the scripts that have done so much to shape both writing and reading throughout the region.

Proposing the Chinese scriptworld as a subject of literary analysis is not to suggest that it is linguistically or culturally monolithic. All the countries that make up this scriptworld have their own native language(s) quite distinct from the others-scriptworld is a many-layered overlapping complex of multiple linguistic, political and cultural systems. However, Chinese script provides a common intellectual edifice. For aspects of literacy and learning were historically shared and developed within the varied, yet constrained parameters of the common writing system.

Script is an issue that still remains virtually undebated in today's discussions of world literature, notwithstanding the vital diagnosis by David Damrosch in 2007 of "global scripts" as a term missing from world literary discourses (Damrosch 200). And despite the predominance in the twentieth century of thinking on how language relates to thought, the "linguistic turn" did not revolve sufficiently to cover the more specific question of how scripts organize, produce and circulate knowledge.

The cultural fields created by the Chinese writing system are particularly fertile ground from which to explore the relations between script and world literature. For the borders of "ideographic" Chinese have often been considered impenetrable by those in "phonetic" script cultures. Various differences between Chinese script and the Roman alphabet have led western thinkers as diverse as Ernest Fenollosa, Ezra Pound, A.C. Graham, Chad Hansen, Roland Barthes, Jacques Derrida and John Gray to assert, in different contexts, the effects produced on thought and culture by the different script systems. For example, it has been hypothesized that the "ideographic" Chinese script shapes nominalist thought while the sound-based Roman alphabet renders the kind of abstract thinking that comprises western realist philosophy. Of the various proposals, the strongest expression is by the philosopher John Gray, who has gone so far as to state that: "Europe owes much of its murderous history to errors of thinking engendered by the alphabet" (Gray 58 ). Such culturalist observations 
on script have prompted many counter considerations and contestations, for example those by Zhang Longxi (1992) and Jing Tsu (2010) to name but two.

The essays collected in this issue bring some of the commentary and debates on writing systems to thinking about world literature in the twenty-first century, offering Chinese script as a distinctive agency not only within the East Asian literary world, but also in a broader field of world literature. By analyzing and demystifying the differences and the similarities between the Chinese scriptworld and the alphabetic world, it aims to provide a starting point for comparative studies between various script cultures across the world, as well as between scripts within the borders of the Chinese scriptworld. In doing so, this issue will broach the central concern: of what significance is script to world literature?

So what this issue does not present is a study of the origin and the development of Chinese writing within China, or East Asia, on which excellent and voluminous scholarship already exists. This issue is intended for scholars and students of world literature. By elucidating the validity of the Chinese scriptworld as an empirical and theoretical structure for articulating a region of world literary history, it offers a base for research into other script regions and illuminates the opportunities that such inquiries bring to world literary discourses. This will allow us to move constructively beyond studies of literature drawn along national—indeed, nationalist—boundaries and on to forming practical, informed strategies for gauging the interrelations, translations and adaptations between and within scriptworlds.

\section{"Speech-writing" and "Idea-writing"}

Implicit in the long-standing theoretical and philosophical discussions about Chinese script is a distinction between "speech-writing" and "idea-writing," or between "phonetic" writing and "ideographic" writing. This distinction problematises the assumption that there is a natural fit between spoken language and the encoding of the sound of speech in a phonetic alphabet, that writing is "visible speech."

For is writing always visible speech? To define all writing as "speech for the eyes" is not only limiting but actually untrue, concealing a number of assump-

1 See John Defrancis, Visible Speech (1989). The idea that written language is a visual representation of speech can be traced at least as far back as the seventeenth century French poet and translator, Georges de Brebeuf's assertion, "Writing-this ingenious art to paint words and speech for the eyes." 
tions under a layer of habituation. The literary conception of writing as visible speech only characterizes one feature of writing. As Derrida problematized as phonocentric in Of Grammatology (1967), by naturalizing the specific cultural conventions of alphabetic writing systems, whether that be Greek, Roman, or Cyrillic, we limit our perspective to just one end of the spectrum of written language instead of seeing the full range.

In recent years, the traditional classification of world literature drawn along national boundaries has been broadened by a more capacious language-based category, such as anglophone, francophone, lusophone, hispanophone, sinophone and others. But while these have successfully exposed the permeability of national boundaries, revealing the transnational interrelations that had gone neglected, the label that is "phone" tends to inhibit the development of another substantial foundation upon which to build a literary model of the world: script.

The conflation of speech and text has consequences most immediately and clearly when applied to translation, a key issue in world literature. Etymologically, translation is the "carrying across" of meaning from one language to another. This description does not take into account script as a factor in the practice of translation. And the "carrying across of meaning" from one written text to another gets mired in the incongruent mix of speech and text. What often results is a problem that is essentially phonocentric.

\section{A Phonocentric Translation Problem over Which We Need Not Despair}

So for example, in post-reformation Europe, there has been a strong preference for, and a continual development of, a literary style that is vocal. A written form of language that gives the effect of a speaking style has been a key standard from at least Romanticism onwards. From Wordsworth to Yeats, "natural words in their natural order" has been the peak that the writer must scale. But if the highest form of literature is that which captures the sound and the rhythm of spoken language, what exactly is the value of Tintern Abbey or No Second Troy when they are mapped onto different phoneme classifications which cannot in any satisfactory way mimic the sound or the rhythm of spoken English?

The inevitable loss of tone, rhythm and sound in the course of translation often leads many literary translators to despair and some straight to the conclusion of untranslatability — what has been called the "despair of translation." But the problem that the sound of speech cannot be carried over to another language is not so much the limit of translation as something inherent in the nature of writing systems. Even a most elaborate writing system, like the Inter- 
national Phonetic alphabet, which has 107 letters as opposed to the English 26, is unable to accurately and exhaustively transcribe actual speech.

Speech sounds vary too widely for one thing, whether due to variations within a single phonological system or to dialect variation. As Saussure pointed out, the "same" phoneme pronounced twice or by two different people is not identical with itself. Its only identity is in its difference from all other phonemes (Saussure 66). And English is now spoken in so many places, evolving in so many different directions, that even native speakers have trouble understanding each other. The phonemes of a Liverpudlian are quite unlike a Texan's. Glaswegians, Singaporeans and Calcuttans may not understand every word of each other's sentences in real time but the written text of their speech will indicate little difference between them.

Great writing often sounds spoken to the ear but this isn't the same as sounding colloquial. Writing that sounds spoken does not actually reproduce the tone, pitch or sound of speech. It only creates an effect of doing so. What we call "voice" is produced by our culturally-acquired cognitive ability to convert letters into imaginary sound patterns. The iambic metre is purportedly as natural as a footstep, or as fundamental as a heart-beat. But this prosody is founded on exposure to written English, not only speech, and certainly not on gait or blood flow. Prosody is an art of creating an acoustic effect, not a transcription of actual sounds, speech or otherwise. In classical Sino-Korean, what would register as natural to the cognitive "ear" would be close to the trochee or even the dactyl. The most perfectly paced English prose may sound merely ponderous to an "ear" trained in a different linguistic environment.

What is invoked when prosody is variously expressed in terms of voice or ear or gait is the speaking subject. So it is easy to think that prosody is about being faithful to the actual speaker, the essence of whom must be carried over to the target language, the failure of which is an indicator of the untranslatability of the original utterance. What the models don't imply is that prosody is actually an acoustic effect produced in the brain by a switching of codes in the mind from vision to sound. The cognitive re-coding may feel natural but the process is anything but. Even when writing closely approximates speech, writingand by extension, translations of writing - can exist autonomously as a distinct form of visual communication in and of itself, beyond its capacity to capture speech. Undue emphasis on sound negates a basic truth about writing, which is that there is always a gap between speech and text. 


\section{The Chinese Script}

This gap is easier to see in Chinese script, or 漢字, "Han characters." The two characters that translate into the words "Chinese script" are pronounced hanzi in Mandarin Chinese, kanji in Japanese, hanja in Korean and hántư' in Vietnamese. Though this two-character compound is pronounced differently according to the language of the speaker, its lexical content remains roughly constant across the linguistic borders.

For over a millennium, it was the norm in "sinoxenic" countries - that is to say, Korea, Japan and Vietnam - to speak in the vernacular but to write in Chinese script, as Chinese characters were the primary, and for centuries the only, written language used across the multilingual terrain that is China, Korea, Japan and Vietnam. Here reading is often so distant from speech that the gap has to be painstakingly bridged by acquired association.

Of course, written Chinese is not purely "ideographic." Chinese characters represent sounds as well as ideas at the same time. And when I refer to the literature of the Chinese scriptworld, I am not saying that Chinese characters were the only script used in China. Nomadic and semi-nomadic cultures within and nearby China have traditionally not adopted hanzi, using instead their own scripts like Manchurian, Tibetan, Mongolian and Uyghur. It was mainly some of the agricultural civilizations geographically surrounding China that adopted hanzi writing.

Today, even with the extremely complex and multidirectional evolution that hanzi has undergone over the course of thirty-five centuries, there are at least 808 Chinese characters commonly used in everyday life across China, Japan and South Korea and Taiwan, which were charted in 2014 by the Northeast Asia Trilateral Forum (see Tyson). The characters will sound differently in China, Korea and Japan, as well as within these countries. To an alphabetic reader, the variation in sound might be perplexing. Thus one might reasonably ask: how can one write if not by transcribing the sound of speech? More pertinently, what relevance has script for theories of world literature and translation?

\section{"Idea-writing"}

Chinese writing was already a fully developed system in the seventeenth century вСЕ. In this region it became the universal script because it was an imperial script. It was the writing system of hegemonic China, adopted in colonial Vietnam from roughly 2100 years ago, in nearby Korea roughly a hundred years after 
that and then in more distant Japan approximately four hundred years thereafter.

To an alphabetic reader, the main difference about this writing system is that there is no general sound-to-letter law that governs it. Related to this feature, is the use of "logographs" (characters that represent words) and "ideographs" (characters that represent ideas). That is not to say that written Chinese only uses "logographs" and "ideographs." On the contrary, most Chinese characters are a combination of logographic, ideographic, phonetic, and other elements, so they indicate sound as well as meaning. Some characters are ideographic in terms of their formation, but no character is purely ideographic, that is to say, a character does not represent an idea without also being part of a lexical structure of meaning.

But if learning to read in the alphabetic system is acquiring the skill to map letters onto sounds, learning to read in Chinese is a process of learning to correlate not only the sound to the letter but the shape (形) of the character to the meaning (意) to the sound (音), forming a cognitive association of the three components of each sign.

So here are some basic examples. First there are Chinese characters that are visually self-evident pictograms (象形: imitating shape), like numbers: 一 (one), 二 (two), and 三 (three). Then there are the pictographic characters that may not immediately yield a clear meaning, for instance, the character, 田, for paddy field, the character, 女, for woman, the character, 子, for child, and the character, 力, for power. But once it is pointed out that $⿴$ is shaped like rice fields, that 女 is the outline of a female body, that 子 looks like the foetal position and that 力 is a simplified form of a plough, the visual signifier powerfully attaches itself to the signified.

In addition to the pictographic, some hanzi characters are ideographic abstractions of thought (指事: indicating event), some of which are fairly straightforward. Representative examples of these are characters that refer to space and time. So the character, 上, meaning "above/top" is indicated by the two strokes above the surface; the character, 下, meaning "below/bottom" is indicated by the two strokes below the surface; and the character, 中, meaning "middle/ centre," is denoted by a stroke through the middle of the object.

Another type is the compound character (會意). These often reverberate with the cultural assumptions of the time in which they were coined. So if one combines the character for paddy field, 田, with that for power, 力, the compound sign, 男, means "man," defining man as someone who has the power to plough the field. When we combine the character for woman, 女, with the character for child, 子, we produce the adjective, 好, meaning "good," reflecting the shared belief that a mother holding a child was simply beautiful, 
and therefore "good." Assemble together the character for woman, 女, with another woman, 女, and another woman, 女, then the assemblage of three women, 茹, swiftly transforms into other meanings, one of which is "adultery," the underbrush of the signified prickling with patriarchal prejudice. ${ }^{2}$

One might pause here to note that in this basic description of hanzi, the sounds of the characters were not mentioned. All the characters discussed above will be spoken differently in each of the four countries. ${ }^{3}$ But because they are not tied to sound alone, they have been used to represent different spoken languages, albeit with enormous effort, as the history of writing in Vietnam, Korea and Japan demonstrate. What is relevant to world literary discussions is that Japanese, Korean and Vietnamese speakers have written in Chinese. Historically, han characters have crossed speech and political boundaries, hence the frequent and casual, labeling of them as "idea-writing" or "ideographic" writing.

As we have seen, the characters are ideographic not in the sense that there is a logical or an exclusive link between the signifier and the signified but in the sense that the signifier provides a visual cue, a mnemonic, for prompting the signified. Learning to read and write in Chinese characters is thus a different experience from alphabetic reading and writing. Literacy is a process of acquiring the recognition of several thousand visual units, one by one, as opposed to the 26 letters of the Roman alphabet. In premodern societies in East Asia, advanced literacy took at least a decade of solid memorization of the classics, which historically only a tiny minority ever achieved. Even basic literacy, roughly 3000 characters, was traditionally confined to the literati class, which was primarily comprised of the male elites.

Meanwhile, a parallel development has progressed throughout history across the Chinese scriptworld, to make the system more phonemic/phonological and more practical. So in Korea, there emerged hangul in the fifteenth century, a phonemic writing system, after a series of more conservative attempts to make Chinese more Korean friendly — known as hyangchal, idu and gugyeol. There emerged in Japan kana — hiragana and katakana, and in Vietnam, Chũ Nôm. In China itself, efforts to alphabetize and simplify Chinese go back to

2 Most han characters have multiple meanings, many of which are regionally specific. For a detailed discussion of traditional pedagogy classified into six types of Han characters or six writings (六書), see McDonald in this issue.

3 Many Han characters yield a range of pronunciations within a single language, depending on the context in which they are used. In addition, they are frequently spoken differently according to regional variation, most notably in China. 
Matteo Ricci's Chinese-Portuguese dictionary in the sixteenth century, culminating in the major and successive linguistic reforms in the twentieth century.

Sketched out in this way, the history of the Chinese writing system might appear as an inevitable progress towards phonetic simplification. But this would be to present an unbalanced picture. While few would contest the benefits of making Chinese more accessible, it would be limiting to see phonetic writing as the end towards which all writing must evolve. Not only because the attributes of "ideographic" writing in Chinese are lost in that judgment but because one loses sight of the fact that alphabetic writing is not really completely phonetic either.

In English, for example, we can think of reading practices where we go straight from the written word to meaning without converting the letter into sound and then sound to meaning. There are plenty of words the definitions of which one could accurately give, words that one might even occasionally use in writing, without knowing how to pronounce them. Technical terms, unusual proper names, loan words and ancient Greek words are usually not converted to phonemes. We all read a great deal without necessarily knowing how the words are said. Plenty of very accomplished translators cannot speak the languages they write in. Reading and writing a language does not necessarily mean you can speak that language and of course the same is true the other way round.

English is also well-known for its poor grapheme-phoneme correspondence. Often in the case of irregular spelling, we find that it is to preserve the etymology of the word, that is to say, to preserve the visual unit of meaning in the word. So for example, the unit "col," meaning pillar, is preserved in colonel and column though they sound very different. The same goes for "san," meaning health, in sanity and insane. This is a kind of "idea-writing" albeit a very weak version.

Finally, there is the writtenness of text that cannot be converted into sound. The flexing of two fingers to mime quotes in conversation is the most obvious case in point. But there is also the impact of italicization and capitalization, the indentation and the paragraph, the colon and the semicolon, the period and the comma, the ellipsis and the dash, the line break and the enjambment-in short, all the typographical choices, the spacing and the structuring of text that produce meaning independently of speech.

This awareness that there is a directly visual route to meaning even in phonetic writing helps us see the importance of script in discussions of world literature. It encourages us to read with both the visual and the auditory processes in mind even when we read alphabetic writing. Translating well and reading well means paying attention to both aspects of writing, which may be more evident 
in Chinese but are not limited to it. In fact one should say that all writing systems are a mix of phonetic and non-phonetic elements and that there is no absolute distinction between the "ideographic" and the alphabetic. This is not to subsume writing under the overarching category of speech but to open up our reading to a more visually inclined prism and to pay attention to how writing encodes meaning in parallel with, but separately from, speech. Seen this way, the inevitable loss of voice in translation can be seen not as evidence for untranslatability but a symptomatic juncture at which the phonocentric bias reveals itself and from which countless opportunities present themselves for the unearthing of textual meaning.

Literature, by Pater's injunction, aspires to the level of music. We are used to being guided by our ear when we write, to try and capture clear vocal cadences, to use our auditory imagination. But literature can also aspire to the level of the visual arts. We might also recognize the ways in which our writing and thought are organized spatially and through visual structure, interplay of patterns and sequence. Calligraphy can be as much help as prosody. By bringing into focus the extraordinarily creative ways in which we can and actually do encode and carry over linguistic meaning visually, we open up translation to all its possibilities.

\section{The Chinese Scriptworld}

No less significant is the flow of communication across the borders of spoken language, nationality and ethnicity that is made possible by script. The Chinese script recorded different languages in the sinoxenic cultures, as well as scores of different Sinitic languages, which in turn divide into scores of dialects and subdialects. The result is a shared scaffolding of concepts derived from canonical texts through which literacy was often acquired. The interconnections built through a common script—a "scriptworld" - are more robust than is usually recognized.

The nine essays in this volume explore the scaffolding that script provides, which complicate even as they clarify the thinking on the interrelations between writing, speech and thought. In "Scriptworlds Lost and Found," David Damrosch returns to his 2007 thesis that "writing systems profoundly shape the thought-world of those who employ them" (Damrosch 200). Excavating the history of the two and a half millennia of cuneiform writing and its rival relations with hieroglyphic and alphabetic writing, Damrosch discusses with reference to modern Vietnam and Korea how a change in the writing system impacts on the reading subject, creating a turmoil of subjectivities. 
This sets the stage for Charles Lock's investigation into phonocentric distortions in western thought in "On roman letters and other stories: An essay in heterographics." Considering rock-carvings, cuneiform, numerals, punctuation, lettering and word-spacing, Lock delineates a counter-tradition of thinking about alphabetic writing, exposing the ways in which Roman script, despite being enrobed in an aura of natural speech, is often resistant to phoneticization and, in doing so, revealing the hegemonic dimensions and iconic value of script.

The alphabetic bias is picked up and examined in relation to translation practices by Judy Wakayabashi in "Script as a Factor in Translation". Illuminating under-theorized issues that emerge in translation practice, ranging across graphological, bibliographic, textual, physical, orthographic, aesthetic, ideological and semiotic concerns, Wakayabashi analyses not only the issues that arise in translations between East Asian languages but points out those regions where, often for political reasons, a common spoken language is written in more than one script, such as the multiple written versions of Sanskrit, spoken Malay written in Arabic and Turkish, and the different writing systems that divide Serbian and Croatian, and Hindi and Urdu.

The immense complexity of the relations between spoken language and script is brought to bear on the historical reception of Chinese in western and Chinese scholarship in Edward McDonald's "The Chinese Script in the Chinese Scriptworld: Chinese Characters in Native and Borrowed Traditions." Taking us through the competing ideological and disciplinary claims that run through the reception of Chinese writing in western scholarship, he grounds the debates in a detailed linguistic discussion of the six key features of written Chinese, challenging some of the misconstruals and cultural projections and allowing us to move constructively beyond them for a developing dialogue between literary theorists, philosophers, linguists, archeologists and anthropologists.

The next two essays, by Karen Thornber and Andrea Bachner, draw deliberately on scripts that had minor status in relation to hegemonic Chinese. Thornber's “The Many Scripts of the Chinese Scriptworld, the Epic of King Gesar, and World Literature" considers the publication and translation history of the world's longest epic, the early Tibetan work, the Epic of King Gesar, and brings to the frame of the Chinese scriptworld the silenced orality and the overlooked minor scripts of the multilingual and multigraphic region that is East Asia. In parallel, Bachner's “Cultural Margins, Hybrid Scripts: Bigraphism and translation in Taiwanese Indigenous Writing" brings to the fore the dynamic between indigenous cultures and the dominant sinographic culture, by examining two recent texts by Taiwanese indigenous authors, Badai and Rahic Talif. 
Bachner's question of whether the indigenous cultures appear as tokens of difference, quickly subsumed in and framed by hegemonic Chinese, is investigated through the prism of the history of writing in Korea by Lim in "From the Universal to the National: The Question of Language and Writing in TwentiethCentury Korea." Locating Korea as the periphery to the literary centre that was China, Lim outlines how the writing system in Korea transitioned from classical into the vernacular, pointing to the larger cultural and political implications of this change.

Moving from Korea to Japan and taking the issue of transfers and exchanges between scripts into a broader domain is Matthew Chozick's "Eating Murasaki Shikibu: Scriptworlds, Reverse-Importation, and the Tale of Genji." Genji is often hailed as the world's earliest novel. But before translations of Genji appeared in English, Chozick reminds us, it had been out of print for nearly two centuries in Japan. He examines how the critical and popular negotiations involving scripts and translations contributed to its success.

Finally, John Duong Phan's essay “The Twentieth-Century Secularization of Han Characters in Vietnam, and their Demotion from the Cosmological to the Aesthetic" charts the history of writing in Vietnam, where, by the early twentieth century, Chinese script was totally eliminated in favour of the alphabetized Vietnamese vernacular. By reflecting on the series of script reforms in the twentieth century, Phan illuminates the cultural and political role that script performs.

Scripts are embedded in their historical and cultural provenance. They manifest in material form the highly specific ways in which cultures record and produce experience. The aim of this special issue is to shed light on the extremely complex literary pattern that evolved within and against the constraints of Chinese script. It is hoped that the basic contours of the Chinese scriptworld help the tracing of a different "figure in the carpet" in the world literary map.

\section{Works Cited}

Damrosch, David. "Scriptworlds: Writing Systems and the Formation of World Literature." Modern Language Quarterly 68: 2 (2007), 195-219.

Derrida, Jacques. Of Grammatology. Trans. Gayatri Chakravorty Spivak. Baltimore: Johns Hopkins UP, 1998.

Gray, John. Straw Dogs: Thoughts on Humans and Other Animals. London: Granta Books, 2002.

Saussure, Ferdinand de. Course in General Linguistics. Trans. Wade Baskin. New York: McGraw-Hill, 1916. 
Tsu, Jing. Sound and Script in Chinese Diaspora. Cambridge: Harvard UP, 2010.

Tyson, Kendall. "808 Ways to Write Chinese, Korean and Japanese: Update." The World of Chinese. Web. 20 Feb. 2016.

Zhang, Longxi. The Tao and the Logos: Literary Hermeneutics, East and West. Durham: Duke UP, 1992. 